\title{
The effect of the reaction conditions on the course of the reactions of hindered phenols with $\mathrm{N}-\mathrm{F}$ reagents
}

\author{
Stojan Stavber* , Marjan Jereb, and Marko Zupan \\ Laboratory for Organic and Bioorganic Chemistry, "Jožef Stefan" Institute and Department of \\ Chemistry, University of Ljubljana, Jamova 39, 61000 Ljubljana, SLOVENIA \\ E-mail: stojan.stavber@ijs.si
}

\section{Dedicated to Prof. Miha Tišler on the occasion of his $75^{\text {th }}$ birthday}

(received 01 Feb 01; accepted 28 Jan 02; published on the web 05 Feb 02)

\begin{abstract}
2,4,6-Trialkyl substituted phenols were selectively transformed in high yield to para-quinols or para-quinol ethers by reaction with the N-fluoro-1,4-diazoniabicyclo[2.2.2]octane salt analogues Selectfluor ${ }^{\mathrm{TM}}$ F-TEDA-BF 4 or Accufluor ${ }^{\mathrm{TM}}$ NFTh in acetonitrile in the presence of water or alcohols. At low temperature 2,4,6-tri-tert-butylphenol in pure acetonitrile gave 2-fluoro and 4fluoro substituted cyclohexadienone products with both reagents, while at elevated temperature 2-fluoro-4,6-di-tert-butylphenol was quantitatively formed. The mechanism postulated the SET proccess, thus forming cation-radical intermediates, as the key step of the reaction was proposed.
\end{abstract}

Keywords: Phenols, oxidation, $p$-quinol derivatives, alkoxylation, N-fluoro diazonia compounds

\section{Introduction}

The extensive application of various types of organofluorine compounds ${ }^{1}$ has resulted in a continuous general interest in their related chemistry. ${ }^{2}$ The introduction of organic molecules incorporating a reactive N-F bond as versatile mild fluorinating reagents ${ }^{3}$ in the last decade has had a revolutionary influence on research in the field of the chemistry of organofluorine molecules. Derivatives of the N-fluoro-1,4-diazoniabicyclo[2.2.2] octane salts promoted by Banks $^{4}$ possess optimal stability/reactivity characteristics and as easy handling, cost effective, commercially available reagents are convenient for routine laboratory work as well as for large scale applications. ${ }^{5}$ The oxidative power of Banks' reagents is lower in comparison with other 
types of »electrophilic« mild fluorinating reagents (fluoroxy derivatives or xenon fluorides), but is among the highest in the series of N-F reagents. ${ }^{6}$ Therefore we can expect a certain decrease in the selectivity of their reactions due to competition between fluorofunctionalisation and oxidation, particularly when oxidisable functional groups or heteroatoms are present in the target molecule. Benzylic and phenolic hydroxy groups which carry a great deal of this oxidation/fluorofunctionalisation competitive dualism can represent a considerable selectivity diminishing factor, but are also useful precursors for selective transformation of organic molecules with electrophilic fluorinating reagents. ${ }^{2 \mathrm{~d}, 7}$

In our continuing interest in the reactions of N-F reagents with phenols ${ }^{7 \mathrm{~d}-\mathrm{f}}$ we now report the transformations of sterically hindered phenols with 1-fluoro-4-chloromethyl-1,4diazoniabicyclo[2.2.2] octane bis(tetrafluoroborate) (2a, Selectfluor ${ }^{\mathrm{TM}}$ F-TEDA-BF 4 ) and its 4hydroxy analogue (2b, Accufluor ${ }^{\mathrm{TM}}$ NFTh).

\section{Results and Discussion}

In a typical experiment we treated 2,4,6-tri-tert-butylphenol (1, Scheme 1) with a 10\% molar excess of F-TEDA-BF 4 (2a) in acetonitrile at $10^{\circ} \mathrm{C}$, and after a work-up procedure we isolated a mixture of 2-fluoro-2,4,6-tri-tert-butyl-cyclohexa-3,5-dienone (3) and 4-fluoro-2,4,6-tri-tertbutyl-cyclohexa-2,5-dienone (4) in 4:1 relative ratio and 85\% cumulative yield. At room temperature the course of the reaction became more complex and besides products 3 and 4, 2fluoro-4,6-di-tert-butylphenol (5) was also detected in the crude reaction mixture, while at $80^{\circ} \mathrm{C}$ an almost quantitative amount of fluoro-dealkylated product 5 was obtained after a few minutes reaction. Almost the same results were obtained when NFTh was used as the reagent. It is evident that in these cases the formation of 2-fluoro and 4-fluoro substituted cyclohexadienone type of products (3 and 4), also observed in our previous report ${ }^{7 \mathrm{f}}$, is a kinetically controlled process, while fluoro-dealkylation gave a thermodynamically more stable product. 2-Fluoro-4,6di-tert-butylphenol (5) could also be obtained after treatment of product 3 with trifluoroacetic acid.

We further investigated the effect of solvent polarity and the presence of an external nucleophile on the course of the reaction of hindered phenol 1 with F-TEDA-BF 4 or NFTh, and found that during reaction of the tested phenol in methanol at room temperature the reagent was not consumed even after a 72 hour reaction time, while at elevated temperatures the reactions resulted in a complex reaction mixture. On the other hand, in a $\mathrm{MeCN} / \mathrm{MeOH}$ 9:1 solvent mixture 2,4,6-tri-tert-butylphenol (1) transformed at $30^{\circ} \mathrm{C}$ selectively to 4-methoxy-2,4,6-tri-tertbutyl-cyclohexa-2,5-dienone (6b, Table) in high yield. The selective formation of para quinol 
ether derivative $\mathbf{6 b}$ was achieved when at least a five fold molar excess of methanol was present in the reacting mixture, while by lowering its concentration, the relative amount of fluorinated products 3, 4, and 5 increased. Under optimised reaction conditions 1 was readily transformed to the corresponding para quinol ethers also when ethanol (entry 3, Table), propanol (entry 4) or 1,2-ethanediol (entry 5) were present in the reaction mixture, while in the presence of water the selectivity of the reaction was found to be poor and only a moderate yield of the para quinol derivative was detected among other, mainly fluorinated reaction products $\mathbf{3}, \mathbf{4}$, and $\mathbf{5}$. On using NFTh as the reagent the reactions also lead to products 6 in high yields. 2,6-Di-tert-butyl-4methylphenol (7) reacted to the corresponding para quinol 8a or para quinol ethers (8b-e) too, and under the mentioned reaction conditions almost quantitative transformation could be achieved with F-TEDA-BF 4 as well as with NFTh. We also established the same results when 2,4,6-trimethylphenol (9) was treated with 2a or 2b. Para quinol 10a or para quinol ethers 10b-f were also formed in excellent yield, except in the case of 2,2,2-trifluoethanol (entry 14) where we succeeded in isolating product 10d only in moderate yield.

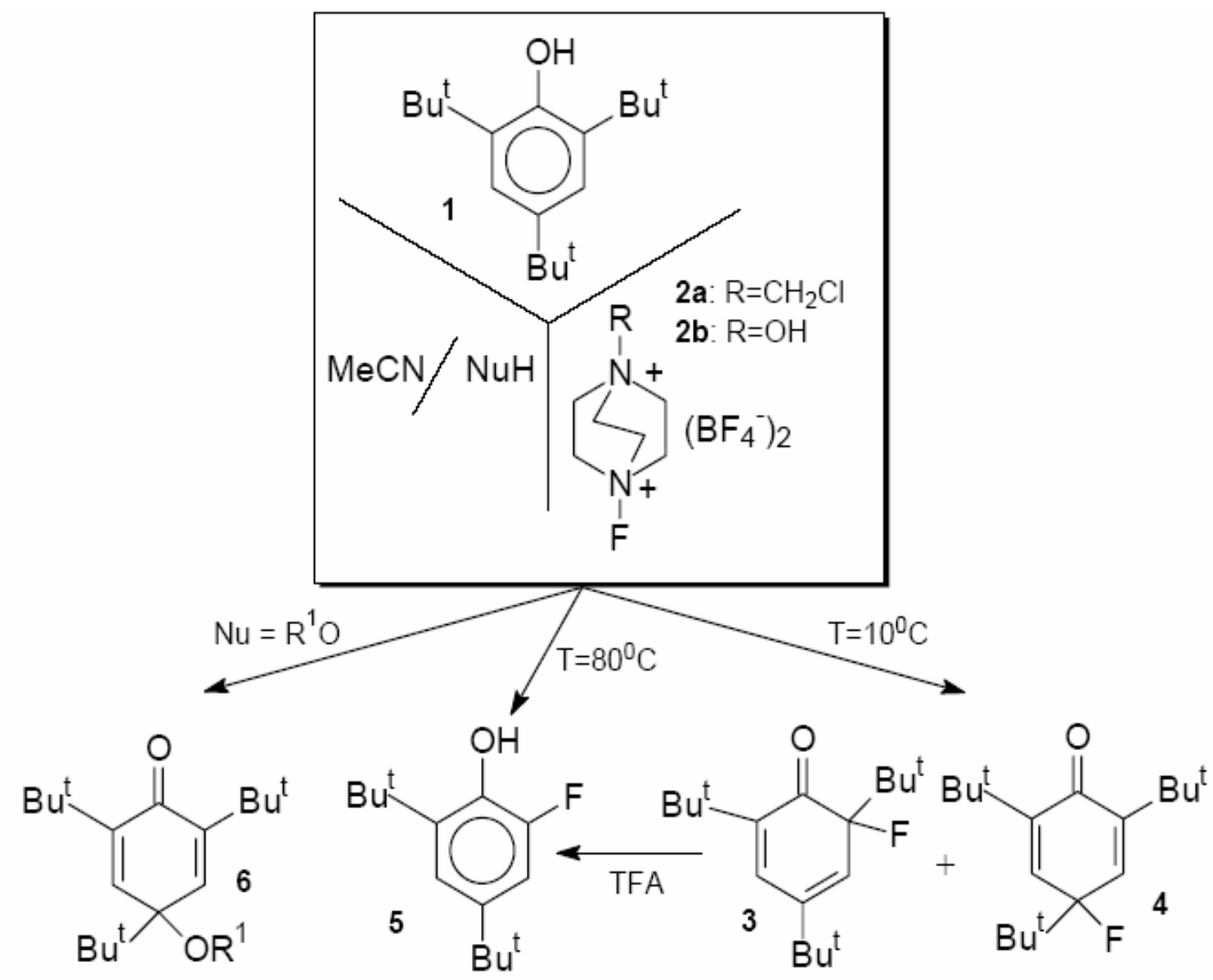

\section{Scheme 1}


Table 1. Mild, selective oxidation of alkyl substituted phenols using Selectfluor ${ }^{\mathrm{TM}}$ F-TEDA (2a) or Accufluor ${ }^{\mathrm{TM}}$ NFTh (2b)

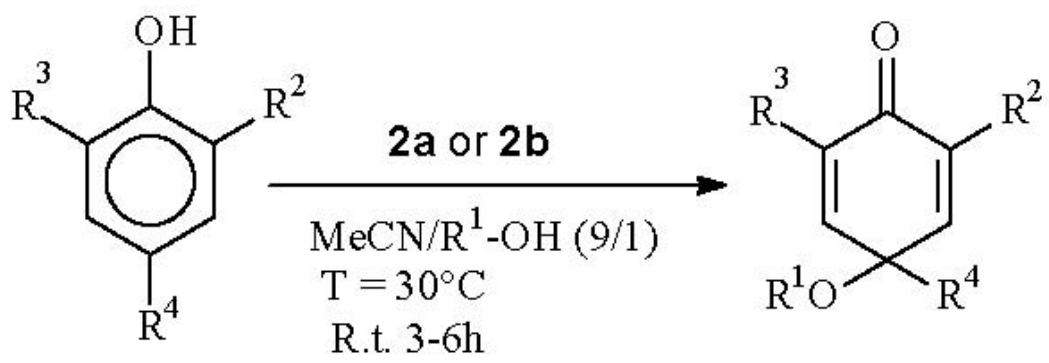

\begin{tabular}{|c|c|c|c|c|c|}
\hline \multirow[t]{2}{*}{ Entry } & \multirow[t]{2}{*}{ Phenol } & \multirow[t]{2}{*}{$\mathrm{R}^{1}$} & \multirow[t]{2}{*}{ Product } & \multicolumn{2}{|c|}{ Yield $(\%)^{\mathrm{a})}$} \\
\hline & & & & $2 a$ & $2 b$ \\
\hline 1 & & $\mathrm{a}: \mathrm{H}$ & & 29 [19] & $32[21]$ \\
\hline 2 & $\mathrm{Bu}^{\mathrm{t}}$ & $\mathrm{b}: \mathrm{Me}$ & & 86 [79] & 90 [82] \\
\hline 3 & & $\mathrm{c}: \mathrm{Et}$ & & $84[75]$ & $83[72]$ \\
\hline 4 & $\mathrm{BL}$ & $\mathrm{d}: \operatorname{Pr}$ & & 86 [77] & 89 [79] \\
\hline 5 & 1 & e: $\mathrm{HOCH}_{2} \mathrm{CH}_{2}$ & 6 & 87 [79] & $91[83]$ \\
\hline 6 & & a: $\mathrm{H}$ & & $88[78]$ & $86[75]$ \\
\hline 7 & & $\mathrm{~b}: \mathrm{Me}$ & & $91[82]$ & 94 [87] \\
\hline 8 & & $\mathrm{c}: \mathrm{Et}$ & & $85[75]$ & $93[81]$ \\
\hline 9 & & $\mathrm{~d}: \mathrm{HOCH}_{2} \mathrm{CH}_{2}$ & & $92[81]$ & $88[78]$ \\
\hline 10 & 7 & e: $\mathrm{CH} 3 \mathrm{OCH} 2 \mathrm{CH} 2$ & 8 & 88 [78] & $91[82]$ \\
\hline 11 & & $\mathrm{a}: \mathrm{H}$ & & $84[76]$ & $88[78]$ \\
\hline 12 & & $\mathrm{~b}: \mathrm{Me}$ & & 93 [85] & $95[86]$ \\
\hline 13 & & $\mathrm{c}: \mathrm{Et}$ & & $92[82]$ & $93[81]$ \\
\hline 14 & Me & $\mathrm{d}: \mathrm{CF}_{3} \mathrm{CH}_{2}$ & & $47[38]$ & $44[32]$ \\
\hline 15 & 9 & e: $\mathrm{HOCH}_{2} \mathrm{CH}_{2}$ & 10 & $83[76]$ & $91[81]$ \\
\hline 16 & & f: $\mathrm{CH} 3 \mathrm{OCH} 2 \mathrm{CH} 2$ & & 87 [79] & $86[77]$ \\
\hline
\end{tabular}

${ }^{a}$ Determined from ${ }^{1} \mathrm{H}$ NMR spectra of crude reaction mixture using benzyl alcohol as internal standard; values in square brackets refer to the isolated pure products.

Considering the results obtained we can conclude that reactions of hindered phenols with Nfluoro-1,4-diazonia bicyclo[2.2.2] octane salt analogues reguire undemanding, but well defined reaction conditions in order to assure the selectivity of the course of reaction. Competition between fluorination and oxidation of target molecules could be completely avoided and by 
choosing appropriate reaction conditions we can effectively and selectively favour one or other process. This fact gives a considerable advantage to the present method over known more or less efficient syntheses of para-quinol derivatives using hypervalent iodine compounds, ${ }^{8,9,10}$ thallium (III) salts, ${ }^{11}$ dimethyldioxirane, ${ }^{12}$ hexacyanoferrate(III) analogues, ${ }^{13}$ manganese dioxide, ${ }^{14}$ oxygenation in the presence of $\mathrm{Cu}(\mathrm{II})^{15}$ or $\mathrm{Fe}(\mathrm{II})^{16}$ catalysts, or electrochemical procedures. ${ }^{17}$

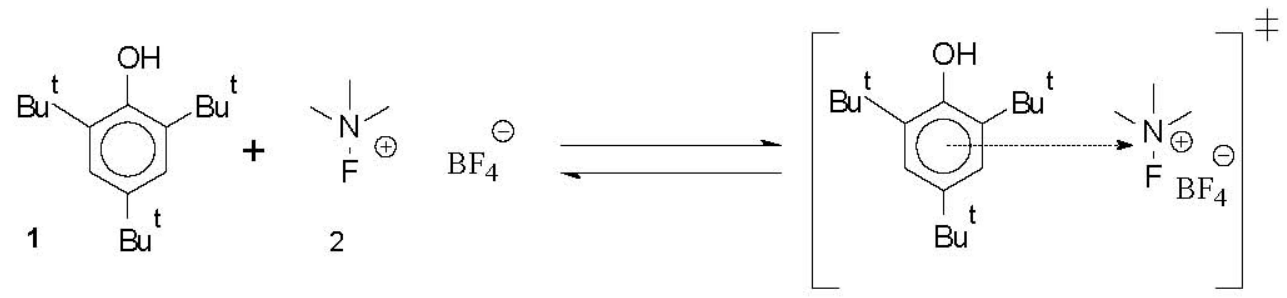

ח-like complex

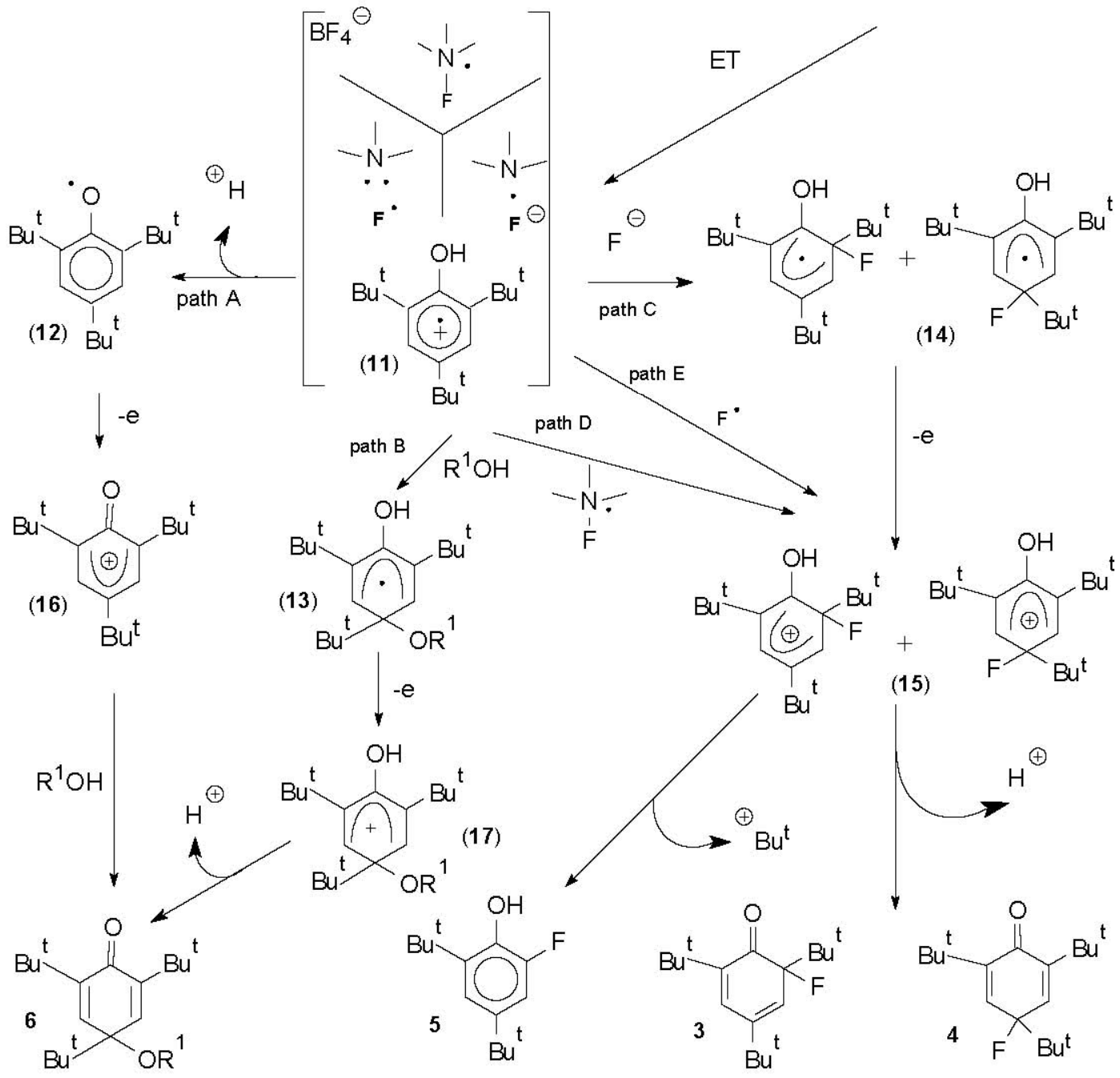

Scheme 2 
Discussion of the possible mechanisms of reactions of "electrophilic" fluorinating reagents with organic compounds is still far from closed. The main subject of dispute is whether the reactions proceed through direct fluorine transfer, or through two-step electron transfer (ET). Fluorine transfer is postulated as a classical $\mathrm{S}_{\mathrm{N}} 2$ process where nucleophilic attack of an electron-rich reaction centre on fluorine results in displacment of the ligand part of the reagent, which must necessarily be a better leaving group than fluoride. The electron transfer mechanism, on the other hand, anticipates the initial formation of a charge-transfer complex between an electron-rich organic molecule and the electron-deficient fluorinating reagent, which after oneelectron transfer transforms to organic molecule cation radical active intermediate as the precursor of fluorinated or non-fluorinated products. ${ }^{3}$ The formation of cation radicals has also been confirmed by ESR and UV spectroscopy in the case of halogenations of activated aromatics with N-halogen reagents (NBS, NCS), ${ }^{18}$ and since N-F reagents are even stronger oxidants, the ET reaction pathway of their reaction with organic molecules is very believable. Nevertheless, it was generally accepted that the course of these reactions is strongly sensitive to the structure of the N-F reagent, the organic molecule and the reaction conditions, and that it is very difficult to define unequivocally the reaction channel through which the products are formed. ${ }^{3}$

On the basis of the data gathered and reported in this paper, we believe that the ET proccess is the main and most probable reaction pathway in the reactions of F-TEDA-BF 4 or NFTh at least with the phenols selected for the present study, and that the formation of the cation-radical (11) is the key step of these reactions (Scheme 2). After electron transfer from the electron-rich phenol 1 to the electron-demanding reaction centre of reagent 2, besides the formation of the cation-radical 11, very reactive fluorine carrying species like $\mathrm{F}^{\cdot}, \mathrm{F}^{-}$and $\mathrm{N}-\mathrm{F}$ could be formed and regulate the course of the reaction. The transformation of cation-radical 11 to the products observed can proceed through at least five main channels depending on reaction conditions.

As $\mathbf{1 1}$ is very acidic, proton loss (path A) thus forming radical intermediate (12), followed by immediate another electron transfer thus forming the cyclohexadienone cation (16) which readily collapses with an external source of nucleophiles to the final product 6, represents the first reaction channel. The second channel also leads to the same product where primary attack of an external nucleophile on cation-radical 11 (path B), followed by electron transfer from radical (13) thus forming cationic intermediate (17), which stabilises by proton loss to the product 6 is anticipated as the possible reaction pathway.

In the formation of the observed fluorinated products all three already mentioned active species carrying a fluorine atom could be involved. In the first case the fluoride anion attacks the cation-radical 11 (path C) at the ortho and para position, thus forming fluoro-substituted radical intermediate (14) which, after second electron transfer, transforms to the corresponding fluoro carbocationic species (15). At this point the reaction could split in two ways depending on the 
reaction temperature. At lower temperatures (15) stabilises through proton loss to 2- or 4-fluorosubstituted cyclohexadienone final products $\mathbf{3}$ and $\mathbf{4}$, while at higher temperatures regioselective ortho attack and stabilisation through tert-butyl cation loss to the thermodynamically more stable 2-fluoro-substituted phenol 5 takes place. Direct formation of fluoro-substituted carbocation intermediate (15) could be reached also after $\mathrm{N}^{*} \mathrm{~F}$ (path D) or $\mathrm{F}^{*}$ (path E) attack on the cationradical (11). In neat acetonitrile the channels $C, D$ and $E$ were found to be the main reaction proccesses, while in the presence of water or alcohols as the source of the external nucleophile, channels A and B were mainly used for product formation.

\section{Experimental Section}

General Procedures. Materials 1-Fluoro-4-chloromethyl-1,4-diazoniabicyclo[2.2.2] octane bis(tetrafluoroborate) (2a, Selectfluor ${ }^{\mathrm{TM}}$ F-TEDA-BF 4 ) from Apollo and 1-fluoro-4-hydroxy1,4-diazoniabicyclo [2.2.2] octane bis(tetrafluoroborate) (2b, Accufluor ${ }^{\mathrm{TM}}$ NFTh as 50\% mixture with $\mathrm{Al}_{2} \mathrm{O}_{3}$ ) from AlliedSignal, 2,4,6-tri-tert-butylphenol (1), 2-6-di-tert-butyl-4methylphenol (7), and 2,4,6-trimethylphenol (9) from Aldrich were used. Combustion elemental analysis of new compounds was performed at Microanalytisches Labor Pascher. ${ }^{1} \mathrm{H}$ and ${ }^{19} \mathrm{~F} \mathrm{nmr}$ spectra were performed on a Varian EM 360L instrument at $60 \mathrm{MHz}$ for proton and at $56.4 \mathrm{MHz}$ for fluorine resonance. $\mathrm{CDCl}_{3}$ was used as solvent and TMS or $\mathrm{CFCl}_{3}$ as internal standard.

\section{Reaction protocol}

To a solution of $5 \mathrm{mmol}$ of substrate $(\mathbf{1}, \mathbf{7}$, or $\mathbf{9}$, Table) in $\mathrm{MeCN}$ or $\mathrm{MeCN} / \mathrm{ROH}$ 9:1 mixture $(50 \mathrm{ml}) 1.95 \mathrm{~g}(5.5 \mathrm{mmol}) \mathrm{F}-\mathrm{TEDA} \mathrm{BF}_{4}$ or $1.76 \mathrm{~g}(5.5 \mathrm{mmol})$ NFTh was added and the reaction mixture stirred at $30^{\circ} \mathrm{C}$ until KI starch paper showed the consumption of the reagent (3-6 hours). The solvent was removed under reduced pressure and the crude reaction mixture dissolved in $\mathrm{CH}_{2} \mathrm{Cl}_{2}$, insoluble material filtered off, the solution washed with water, dried over $\mathrm{Na}_{2} \mathrm{SO}_{4}$, and the solvent evaporated. The isolated crude reaction mixtures were analysed by ${ }^{1} \mathrm{H}$ and ${ }^{19} \mathrm{~F}$ nmr and TLC, and pure products were obtained after flash chromatography over $\mathrm{SiO}_{2}$. The spectroscopic data for the known compounds $5^{13}, \mathbf{3}$ and $4^{19}, \mathbf{6 a}, \mathbf{6 b}, \mathbf{8 b}$ and $10 \mathbf{b}^{11}, \mathbf{6 \mathbf { e } ^ { 2 0 }} \mathbf{6 c}$ and $\mathbf{6} \mathbf{d}^{21}, \mathbf{1 0 a}$ and $\mathbf{1 0} \mathbf{c}^{8}, \mathbf{1 0} \mathbf{d}^{22}, \mathbf{8} \mathbf{a}^{9}$, and $\mathbf{8} \mathbf{c}^{14}$ were in agreement with the literature, while unknown products were fully characterised as listed below.

2,6-Bis(1,1-dimethylethyl)-4-(2-hydroxyethoxy)-4-methylcyclohexa-2,5-dienone (8d). Oily; ${ }^{1} \mathrm{H}$ NMR: $\delta$ 1.27-1.40(br s, 21H); $\delta 3.37(\mathrm{t}, 2 \mathrm{H}, \mathrm{J}=5 \mathrm{~Hz}) ; \delta 3.70(\mathrm{t}, 2 \mathrm{H}, \mathrm{J}=5 \mathrm{~Hz}) ; \delta 6.50(\mathrm{~s}, 2 \mathrm{H})$. IR (neat): 1664, $1642 \mathrm{~cm}^{-1}$. MS: m/z 280(10); 265(76); 224(100); 219(30); 209(98); 205(47); 163(43); 149(26); 91(21); 77(13); 57(97); anal. calcd. for $\mathrm{C}_{17} \mathrm{H}_{28} \mathrm{O}_{3}$ : C 72.82, $\mathrm{H}$ 10.06; found: C 
72.72, H 10.19.

2,6-Bis(1,1-dimethylethyl)-4-(2-methoxyethoxy)-4-methylcyclohexa-2,5-dienone

(8e). Hygroscopic liquid compound; ${ }^{1} \mathrm{H}$ NMR: $\delta 1.23-1.37($ br s, $21 \mathrm{H}) ; \delta 3.40(\mathrm{br} \mathrm{s}, 7 \mathrm{H}) ; 6.50(\mathrm{~s}, 2 \mathrm{H})$. IR (neat): 1663; $1641 \mathrm{~cm}^{-1}$. MS: m/z 294(3); 279(18); 238(39); 223(20); 219(13); 205(34); 189(12); 177(11); 161(26); 91(18); 77(16); 59(100); anal. calcd. for $\mathrm{C}_{18} \mathrm{H}_{30} \mathrm{O}_{3}$ : C 73.43, $\mathrm{H} \mathrm{10.27;}$ found: C 73.59, H 10.39.

4-(2-Hydroxyethoxy)-2,4,6-trimethylcyclohexa-2,5-dienone (10e). Hygroscopic liquid compound; ${ }^{1} \mathrm{H}$ NMR: $\delta 1.38(\mathrm{~s}, 3 \mathrm{H}) ; \delta 1.88(\mathrm{~s}, 6 \mathrm{H}) ; 2.90(\mathrm{br} \mathrm{s}, 1 \mathrm{H}) ; 3.23-3.73(\mathrm{~m}, 4 \mathrm{H}) ; 6.55(\mathrm{~s}, 2 \mathrm{H})$. IR (neat): 1672; $1635 \mathrm{~cm}^{-1}$. MS: m/z 196(12); 181(7); 168(1); 152(48); 135(100); 124(14); 109(20); 91(46); 79(18); HRMS calcd for $\mathrm{C}_{11} \mathrm{H}_{16} \mathrm{O}_{3}$ 196.1099, found 196.1104; anal. calcd. for $\mathrm{C}_{11} \mathrm{H}_{16} \mathrm{O}_{3}$ : C 67.32, $\mathrm{H}$ 8.22; found: C 66.59, H 8.26.

4-(2-Methoxyethoxy)-2,4,6-trimethylcyclohexa-2,5-dienone (10f). Hygroscopic liquid compound; ${ }^{1} \mathrm{H}$ NMR: $\delta 1.33(\mathrm{~s}, 3 \mathrm{H}) ; \delta 1.87(\mathrm{~s}, 6 \mathrm{H}) ; 3.33(\mathrm{br} \mathrm{s}, 7 \mathrm{H}) ; 6.50(\mathrm{~s}, 2 \mathrm{H})$. IR (neat): 1671; $1640 \mathrm{~cm}^{-1}$. MS: m/z 210(4); 195(8); 182(1); 178(1); 152(44); 135(100); 121(4); 107(13); 91(47); 79(19); 59(84); anal. calcd. for $\mathrm{C}_{12} \mathrm{H}_{18} \mathrm{O}_{3}$ : C 68.54, H 8.63; found: C 68.45, H 8.78.

\section{Acknowledgements}

The authors are grateful to Dr. George Shia from AlliedSignal for free samples of Accufluor ${ }^{\mathrm{TM}}$ NFTh, and the Ministry of Science and Technology of the Republic of Slovenia for financial support. 


\section{References and Notes}

1. Banks, R. E.; Smart, B. E.; Tatlow, J. C. Eds. Organofluorine Chemistry. Principles and Commercial Applications, Plenum Press: New York, 1994.

2. (a) Filler, R.; Kobayashi, Y.; Yagupolskii, L. M., Eds; Organofluorine Compounds in Medicinal Chemistry and Biomedicinal Application, Elsevier: Amsterdam, 1993. (b) Hudlicky, M.; Pavlath, A. E. Eds. Chemistry of Organic Fluorine Compounds II. A Critical Review, ACS Monograph 187; ACS: Washington DC, 1995. (c) Resnati, G.; Soloshnok, V. A., Eds. Fluoroorganic Chemistry: Synthetic Challenges and Biomedicinal Rewards, Tetrahedron Symposia-in-Print No. 58, Tetrahedron 1996, 52, 1. (d) Baasner, B.; Hagemann, H.; Tatlow, J. C. Eds. Methods of Organic Chemistry (Houben-Weyl) Vol 10a and 10b: Organo-Fluorine Compounds. Thieme: New York, 1999.

3. Lal, G. S.; Pez, G. P.; Syvret, R. G. Chem. Rev. 1996, 96, 1737.

4. Banks, R. E.; Mohialdin-Khaffaf, S. N.; Lal, S. G.; Sharif, I.; Syvret, R. G. J. Chem. Soc., Chem. Commun. 1992, 595.

5. (a) Banks, R. E. J. Fluorine Chem. 1998, 87, 1. (b) Stavber, S.; Zupan, M. Tetrahedron Lett. 1996, 37, 3591. (c) Umemoto, T.; Nagayoshi, M. Bull. Chem. Soc. Jpn. 1996, 69, 2287.

6. (a) Gilicinski, A. G.; Pez, G. P.; Syvret, R. G.; Lal, G. S. J. Fluorine Chem. 1992, 59, 157.

(b) Differding, E.; Bersier, P. M. Tetrahedron 1992, 48, 1595.

7. (a) Stavber, S.; Košir, I.; Zupan, M. J. Chem. Soc., Chem. Commun. 1992, 274. (b) Stavber, S.; Zupan, M. Tetrahedron Lett. 1993, 34, 4355. (c) Stavber, S.; Košir, I.; Zupan, M. J. Org. Chem. 1997, 62, 4916. (d) Zupan, M.; Iskra, J.; Stavber, S. Bull. Chem. Soc. Jpn. 1995, 68, 1655. (e) Stavber, S.; Zupan, M. Synlett 1996, 693. (f) Stavber, S.; Jereb, M.; Zupan, M. Synlett 1999, 1375.

8. Adler, E.; Andersson, G.; Edman, E. Acta Chem.Scand. B 29, 1975, 909.

9. McKillop, A.; McLaren, L.; Taylor, R. J. K. J. Chem. Soc., Perkin Trans. 1 1994, 2047.

10. (a) Pelter, A.; Elgendy, S. Tetrahedron Lett. 1988, 29, 677. (b) Pelter, A.; Elgendy, S. M. A. J. Chem. Soc., Perkin Trans I 1993, 1891.

11. McKillop, A.; Perry, D. H.; Edwards, M.; Antus, S.; Farkas, L.; Nógrádi, M.; Taylor, E. C. J. Org. Chem. 1976, 41, 282.

12. Crandall, J. K.; Zucco, M.; Kirsch, R. S.; Coppert D. M. Tetrahedron Lett. 1991, 32, 5441.

13. Tashiro, M.; Yoshiya, H.; Fukata, G. J. Org. Chem. 1981, 46, 3784.

14. Dietl, H.; Young, H. S. J. Org. Chem. 1972, 37, 1672.

15. Capdevielle, P.; Maumy, M. Tetrahedron Lett. 1983, 24, 5611.

16. Homs, N.; de la Piscina, P. R.; Borrull, F. J. Chem. Soc., Chem. Commun. 1988, 1075.

17. (a) Ronlan, A.; Parker, V. D. J. Chem. Soc. (C) 1971, 3214. (b) Nilsson, A.; Ronlan, A.; 
Parker, V. D. J. Chem. Soc., Perkin Trans. 1 1973, 2337.

18. Eberson, L.; Hartshorn, M. P.; Radner, F.; Persson, O. J. Chem. Soc., Perkin Trans. 2 1998, 59.

19. Polishchuk, V. R.; German, L. S. Tetrahedron Lett. 1972, 51, 5169.

20. Tashiro, M.; Fukata, G. Heterocycles 1979, 12, 1551.

21. Tashiro, M.; Fukata, G.; Yoshiya, H. Synthesis 1979, 12, 988.

22. Quinkert, G.; Kleiner, E.; Freitag, B. J.; Glennberg, J.; Billhardt, U. M.; Cech, F.; Schmieder, K. R.; Schudok, C.; Steinmetzer, H. C.; Bats, J. W.; Zimmermann, G.; Dürner, G.; Rehm, D.; Paulus, E. F. Helv. Chem. Acta 1986, 69, 469. 